\title{
Comparative Study to Evaluate the Antimicrobial Effect of MTAD, 17\% EDTA, and 3\% NaOCl- Against Enterococcus faecalis in Primary Teeth for Root Canals Therapy (in Vitro Study)
}

\author{
Sarmad A. Hameed ${ }^{1}$ Sana'a Abdulrazzaq Ibrahim ${ }^{2}$ Suhad Al-Nasrawi ${ }^{3}$ \\ ${ }^{I}$ Department of Oral Medicine and oral Pathology, Faculty of Dentistry, University of Kufa, AL - Najaf, Iraq, \\ ${ }^{2}$ Department of Basic Sciences, Department of prosthodontic, Faculty of Dentistry, University of Kufa, AL - Najaf \\ Iraq. ${ }^{3}$ Department of Conservative, Faculty of Dentistry, University of Kufa, AL-Najaf, Iraq
}

\begin{abstract}
Aim: This study presented to compare the antimicrobial effect of MTAD, 17\% EDTA, and 3\% $\mathrm{NaOCl}$, against Enterococcus faecalis (E. faecalis).

Methodology: The study utilized 40 extracted human primary teeth with single root canal. The samples were instrumented and sterilized, and then, these teeth were infected with E. faecalis for 2 weeks, after that tooth were divided randomly into 2 groups according to the irrigants used. All the samples were incubated in brain heart infusion (BHI) broth. Irrigation processes were completed according to each material instruction. The effectiveness of irrigants was evaluated by comparison between the pre-irrigation and post- irrigation samples using serial dilution (CFU/ml).
\end{abstract}

Statistical analysis was done using one-way anova with dunnett t3 post hoc test.

Results: all samples treated with MTAD showed nearly complete absence of bacteria. the samples treated $3 \% \mathrm{NaOCl}$ and $17 \%$ EDTA showed similar result to the first group, Statistical analysis of the data using dunnett $\mathrm{t} 3$ test showed there is no significant difference between the groups $(\mathrm{P}>0.05)$.

Conclusion: The study concluded that MTAD was effective as $3 \% \mathrm{NaOCl}-17 \%$ EDTA against E. faecalis.

Keywords: BHI broth, Enterococcus faecalis, 17\% EDTA, MTAD, 3\% NaOCl, Primary teeth.

\section{Introduction}

Microorganisms are playing a fundamental role in etiology of pulp and periradicular lesions ${ }^{[1]}$. Successful therapy of root canal relies on triad of instrumentation, disinfection and obturation ${ }^{[2]}$. The major determinant in the healing of periapical tissues is the disinfection of the root canal ${ }^{[1]}$. This is happen though the use of antimicrobials and chemo mechanical preparation, which are effective in reducing the bacterial load, some bacteria can still persist ${ }^{[3]}$. One among the facultative organism is Enterococcus faecalis, which is persistently found in failures of root canal treatment ${ }^{[4]}$, and is resistant to various intracanal medicaments ${ }^{[5]}$. The microorganisms, which found in the root canals of permanent teeth are similar to those in the root canals of deciduous teeth ${ }^{[6}$, 7]. Though, a commonly used root canal irrigant, is sodium hypochlorite $(\mathrm{NaOCl})$, it has an unpleasant taste and odor it does not consistently system for disinfect the root canal ${ }^{[8]}$, and is toxic, when extruded into the periradicular tissues ${ }^{[9]}$. So, a search for better root canal irrigant continues, because of these limitations. 


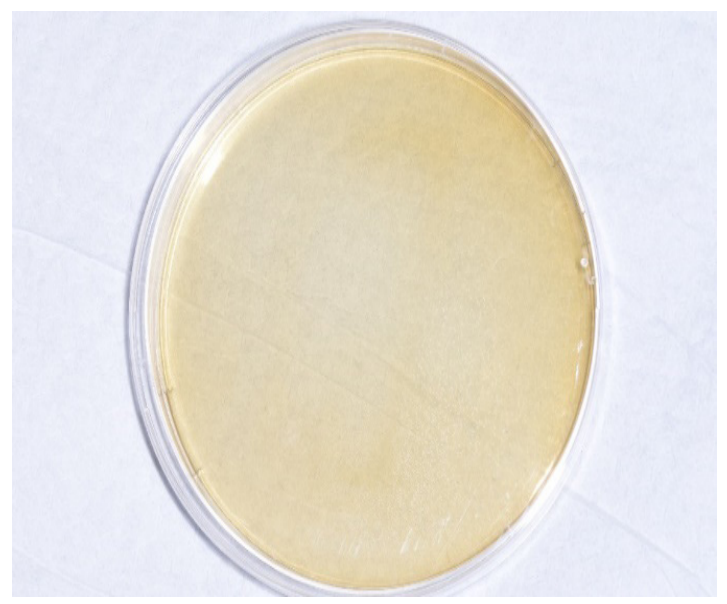

Figure 1: bile esculin blood agar plate.

Torbinejad in 2003 introduced, a new irrigant, such as MTAD which is a mixture of Doxycycline, citric acid, and detergent (Tween-80) ${ }^{[7]}$, which is capable of safely removing the smear layer ${ }^{[10]}$, and eliminating E.faecalis ${ }^{[11]}$.The present study sought to compare the antimicrobial efficacy of MTAD, $3 \% \mathrm{NaOCl}$, and $17 \%$ EDTA against E.faecalis.

\section{Methodology}

\section{Material and Method}

Forty extracted single rooted of human primary teeth, were collected from children, aged 6-7 years, (Tow-third of the root length, at least should be presented). Crowns of teeth, were cut leaving only the roots. Determination of working length should be completed by radiograph. Instrumentation of the roots, to size $30 \mathrm{~K}$-type file. Then cleaning the samples with normal saline, and sterilized by ${ }^{[12]}$.

E.faecalis, should be isolated from infected root canals. Many samples were taken from chronic infected roots that suspected to be inhabitant with E.faecalis. there was a special test called bile esculin test (selective test for E.faecalis) used for first identification of bacteria(figure 1) where, such a black deposit appears after 24 hours of samples culturing (figure 2). Then E.faecalis, further detecting by another way called vitek 2 system for more accuracy (figure 3 ).

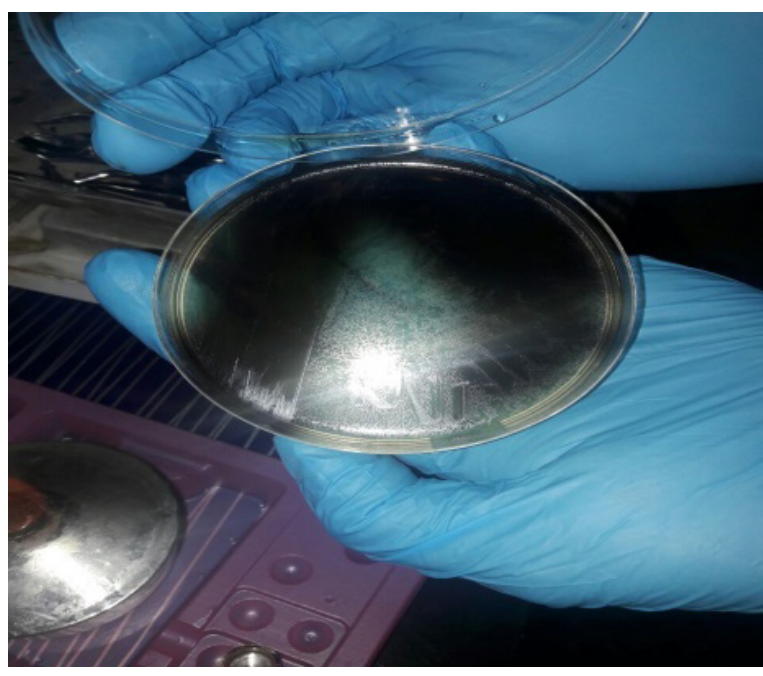

Figure 2:E.faecalis (black deposit) in bile esculin agar

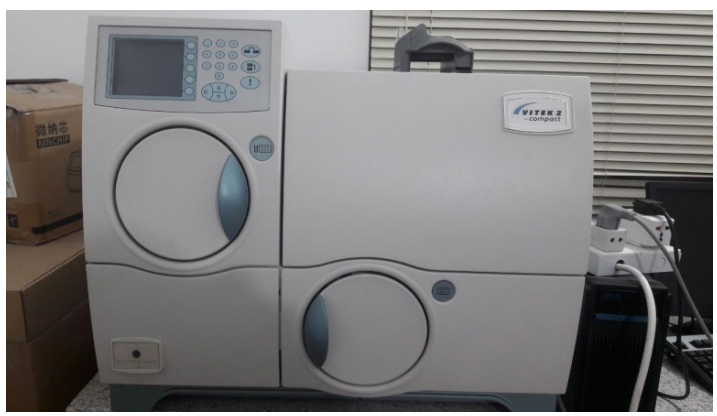

Figure 3: vitek 2 system

The tooth specimens sterilized and then inoculated with E.faecalisthat, after that was cultured in BrainHeart Infusion (BHI) broth at $37^{\circ} \mathrm{C}$. In order to inject the broth suspension inside root canal, 30 gauge needle was used. All specimens tooth must be immersed in broth at $37^{\circ} \mathrm{C}$ to allow bacterial growth (figure 4). Medium in this process should be changed once a week for each 4 respectively weeks. Two weeks' period was chosen for inoculation of bacteria, as recognizable number of colonies of bacteria has been produced after it. After this process, teeth were removed from the bacterial culture. Then we covered the root apices with Cavit ${ }^{\mathrm{TM}}$. After that, the end of each tooth specimen was wiped with3\%sodium hypochlorite in order to disinfect the outside of the tooth before irrigation treatment ${ }^{[13]}$.

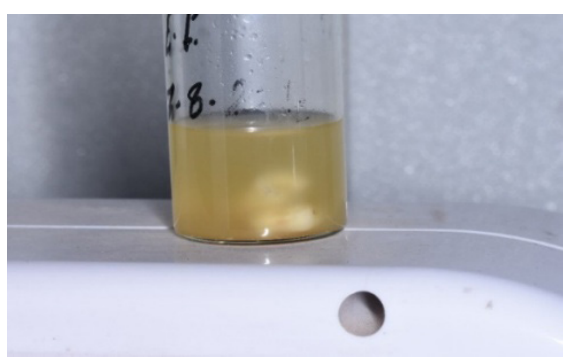

Figure 4: teeth specimens in brain heart infusion broth. 
Then, all samples were divided randomly in to 2 groups, for experimental procedure of irrigation materials. Paper point that used for taking swap should be sterile, this swap from root canal (pre samples) before irrigation procedures. Importantly, we must be irrigated the root canal with normal saline and then preoperative swap was taken; normal saline here acts as good media for inoculation the content of canal.

\section{Irrigation procedure:}

Group 1: In this group, 20 roots samples, each root canal was irrigated firstly with $2 \mathrm{ml} 3 \% \mathrm{NaOCl}$, then normal saline cleaning, followed by irrigation with $17 \%$ EDTA, and final irrigation with normal saline ${ }^{[14]}$.

Group 2: In this group, 20 samples irrigated with MTAD, $2 \mathrm{ml}$ of MTAD used for root canal irrigation, followed by irrigation with normal saline ${ }^{[15]}$.

Sterile paper point, used for taking post irrigation samples from the root canal. Both pre and post sample, are kept in Eppendorf tubes, special tubes, which containing $1 \mathrm{ml}$ of normal saline, (figure 5) and then transferred to the laboratory, for serial dilution, and bacterial count by using $\mathrm{cfu} / \mathrm{ml}$ procedure (figure6).

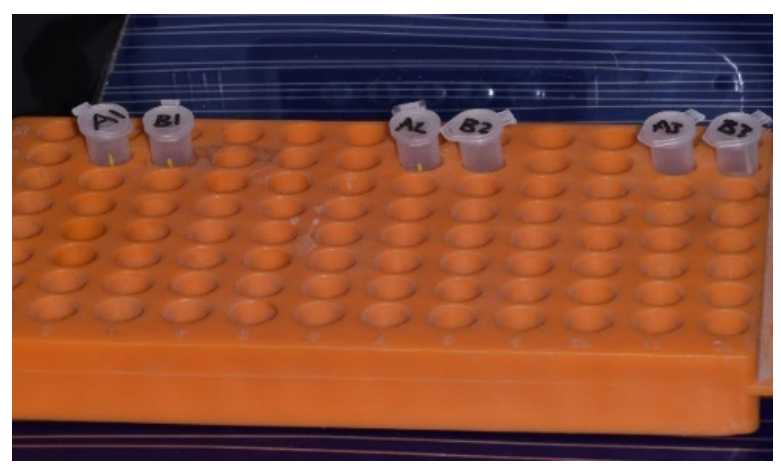

Figure 5: pre and post irrigation samples.

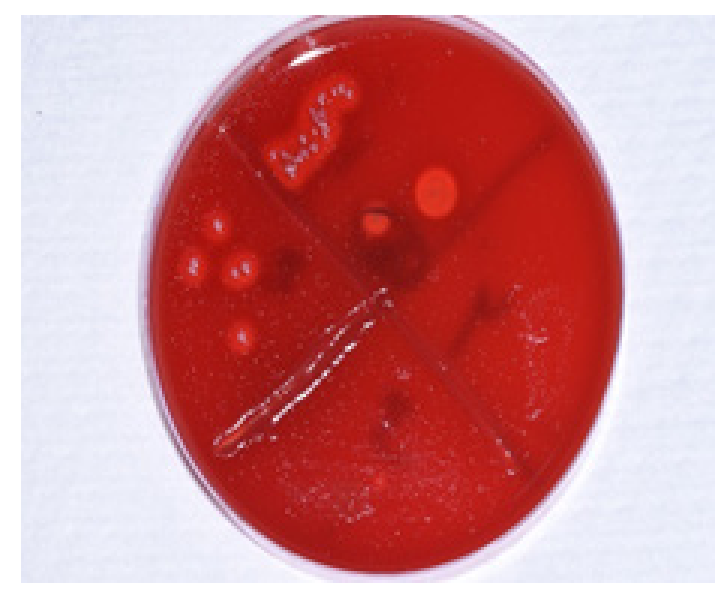

Figure6: colonies of E.faecalis in the blood agar plate.

\section{Results}

In this study the number of bacterial colonies in both irrigation regimens are reduction as in table (1).

Table 1: The values of antibacterial effect of the Tow irrigant methods used in the study

\begin{tabular}{|l|l|l|l|l|}
\hline Groups & Mean & Std. Deviation & Minimum & Maximum \\
\hline MTAD & 98.037 & 1.029 & 95.45 & 100.00 \\
\hline NAOCL\&EDTA & 99.187 & 1.975 & 94.00 & 100.00 \\
\hline
\end{tabular}

Result of one way anova revealed that there is no significant difference between antibacterial efficacy of both groups $\mathrm{p}>0.05$ shown in (table 2 ).

Table 2: Statistical values of one wayanova analysis for both Groups

\begin{tabular}{|l|l|l|l|l|l|}
\hline & Sum of Squares & df & Mean Square & F & Sig. \\
\hline Between Groups & 5832.821 & 2 & 2916.410 & 240.724 & .161 \\
\hline Within Groups & 508.837 & 42 & 12.115 & & \\
\hline Total & 6341.658 & 44 & & & \\
\hline
\end{tabular}

Levene statistics $=17.993, \mathrm{df}=2, \mathrm{p}$ value $=0.161$. 
Table 3: The antibacterial effect of the irrigant methods by Dunnett $\mathbf{t} 3$ post hoc test, Comparison Study.

Comparisons between groups using Dunnett T3

\begin{tabular}{|l|l|l|l|l|l|}
\hline \multirow{2}{*}{ (I) Group } & \multirow{2}{*}{$\begin{array}{l}\text { Mean Difference } \\
\text { (J-J) Group }\end{array}$} & \multirow{2}{*}{ Sig. } & \multicolumn{2}{|l|}{$\mathbf{9 5 \% \text { Confidence Interval }}$} \\
\cline { 3 - 6 } & & & & Lower Bound & Upper Bound \\
\hline \multirow{2}{*}{ MTAD } & NaOCL\&EDTA & -1.151 & $.161[\mathrm{NS}]$ & -2.636 & .335 \\
\cline { 2 - 6 } & & & & & \\
\hline
\end{tabular}

There is no significant difference showedin comparisons between MTAD and 3\% NaOCL - 17\%EDTA group, the $p$ value $=0.161(p>0.05)$. Table 4: The antibacterial effect for pre and post samples for both groups

\begin{tabular}{|l|l|l|l|l|l|l|l|}
\hline \multirow{2}{*}{ Groups } & \multicolumn{3}{l}{ Paired Samples Statistics } & \multirow{2}{*}{ T value } & \multirow{2}{*}{ P value } & \multirow{2}{*}{ Effect size } \\
\cline { 2 - 5 } & \multicolumn{2}{|l|}{ PRE } & \multicolumn{2}{l|}{ Post } & & \\
\cline { 2 - 8 } & Mean & SD & Mean & SD & & & \\
\hline MTAD & 3.675 & 1.251 & .067 & .032 & 11.202 & $.000[\mathrm{HS}]$ & 2.892 \\
\hline NaOCL\& EDTA & 2.041 & .626 & .014 & .034 & 12.394 & $.000[\mathrm{HS}]$ & 3.200 \\
\hline
\end{tabular}

$\mathrm{Df}=14$

In this study, result showed the reduction in the means percentage of the post samples of bacterial colonies for both methods, as in table 4, but the large effect size is 2.892 in the MTAD group, and $(3 \% \mathrm{NaOCL}-17 \%$ EDTA) group is 3.200 effectsize, as in table 4.

\section{Discussion}

In order to eliminate the bacteria and their products, and the substrate from the root canal system of teeth, doing root canal treatment ${ }^{[16]}$, so this process is the main aims for our study. In this process, the use of irrigation solution is essential to ensure bacterial elimination, and removal of organic tissue pieces ${ }^{[17]}$.Maximum tissue dissolving effect on the necrotic tissues, when we have maximum anti-bacterial effect of irrigant, and the least toxic effect on the peripheraltissues are some important features of an ideal root canalirrigant ${ }^{[18]}$. Primary teeth have the complex morphology, and the irregularity of the root canals, which of negatively affect the success of chemo-mechanical endodontic treatment ${ }^{[19]}$. The most commonly employed root canal irrigantis sodiumhypochlorite, till now ${ }^{[20]}$, the antimicrobial activity of $\mathrm{NaOCl}$ is by the release of hypochlorous acid $(\mathrm{HOCl})$, oxidative action of this acid on sulfhydryl groups of bacterial enzymes, by the action of $(\mathrm{HOCl})$ will disrupted the metabolism of the microorganism ${ }^{[20]}$. Sodium hypochlorite, it is an effective antibacterial agent, but $\mathrm{NaOCl}$ is toxic when extruded to the periradicular tissue $^{[18]}$. Many primary teeth needed treatment for root canal, permanent tooth follicles can be damaged by $\mathrm{NaOCl}$ during treatment, and also peripheral tissues and oral mucosa. Therefore, a new irrigants should be found, research for that must be continues. MTAD, new material introduced in 2003, it was subjected to various test procedures, in order to evaluate its efficacy, it was compared with various commonly used irrigants. The antimicrobial activity of both MTAD over $3 \% \mathrm{NaOCl}$ seen in this study are inconformity with the findings of Shabahang, and Torabinejad's study ${ }^{[11,21]}$.

The most important organism in this study was $E$. faecalis. Therefore, it was selected, because it is most commonly isolated in endodontic retreatment of apical periodontitis $^{[4]}$, sodium hypochlorite ${ }^{[20]}$, potassium iodide $^{[22]}$ or calcium hydroxide ${ }^{[23]}$ chemical material irrigants had been identified to have a resistant currently when used, and has been found to survive as a monoinfection in root canals ${ }^{[2]}$. There is many previous in vitro studies, which have shown a high level of susceptibility 
of E. faecalis to MTAD, this solution was diluted 200 times and still has the same efficacy of, while $\mathrm{NaOCl}$ loses its antibacterial activity against the E. faecalis beyond 32 times dilution ${ }^{[11]}$.

MTAD, its acting by removing the smear layer of bacteria with significantly less erosion of the dentinal tubules in comparison with EDTA(10). MTAD, when was evaluated for biocompatibility, it was prove to be less cytotoxic, and more safer than Eugenol, $\mathrm{Ca}(\mathrm{OH}) 2$ paste,5.25\% $\mathrm{NaOCl}, 3 \% \mathrm{H} 2 \mathrm{O} 2,0.12 \%$ Chlorhexidine gluconate $^{[24]}$. The antimicrobial effectiveness of MTAD, by anticollagenase activity of Doxycycline, which it causes low $\mathrm{Ph}$ and have ability to be released gradually over time ${ }^{[10]}$, also its action by citric acid was facilitated the removing the organic and inorganic substances. Surface tension of solution reduces on the dentinal tubule by Tween- 80 ,therefore, allows Doxycycline to penetrated more deeper intothe tubules. Capacity of MTAD to kill E.faecalis after a mere exposure of 5 minutes, which is one of the significant features of this material, making it useful in the clinical situation. However, this effect was not seen with $\mathrm{NaOCl}^{[25]}$. Newberry et al. showed that MTADkilled most strains of E.faecalis when diluted 1:512 times and inhibited most strains of E.faecalis growth when diluted 1:8192 times ${ }^{[26]}$. Thus MTAD has ideal properties for root canal irrigant. The results of the our study was identicalto the findings of Portenier et al ${ }^{[27]}$, Ghoddusi et al ${ }^{[28,29]}$, and Davis et al ${ }^{[30]}$, while studies done by Dunavant et $\mathrm{al}^{[29]}$, Baumgartner et al ${ }^{[30]}$, Krause et $\mathrm{al}^{[31]}$ are differences with these results. These differences in the results due to differences in our methodology and variance in strains tested, and the modification in our processing.

\section{Conclusion}

Conclusion based on the data of the present study, biopure MTAD has an effectiveness as $3 \% \mathrm{NaOCl}-17 \%$ EDTA. However, more in vitro and in vivo studies are important to prove the using of MTAD as good irrigant against $\mathrm{E}$. faecalis.

\section{Conflict of Interest - Nil}

Source of Funding- Self

Ethical Clearance - Not required

\section{References}

[1]. Kakehashi S, H Stanley, R Fitzgerald. The effects of surgical exposures of dental pulps in germ-free and conventional laboratory rats. Oral Surgery, Oral Medicine, Oral Pathology, 1965. 20(3): p. 340-349.

[2]. Ingle JI. Root canal obturation. J Am Dent Assoc. 1956;53(1):47-55.

[3]. Sjögren U, et al., Influence of infection at the time of root filling on the outcome of endodontic treatment of teeth with apical periodontitis. International endodontic journal. 1997; 30(5): p. 297-306.

[4]. Rôças IN, JF Siqueira Jr, KR Santos. Association of Enterococcus faecalis with different forms of periradicular diseases. Journal of endodontics. 2004; 30(5): p. 315-320.

[5]. Tomic-Karovic K. Comparative study of the bacterial flora in the surroundings, the root canals and sockets of deciduous molars. Int. Dent. J. 1971; 21: p. 375-388.

[6]. Chang YC, et al., The effect of sodium hypochlorite and chlorhexidine on cultured human periodontal ligament cells. Oral Surgery, Oral Medicine, Oral Pathology, Oral Radiology, and Endodontology. 2001; 92(4): p. 446-450.

[7]. Torabinejad $M$, et al., A new solution for the removal of the smear layer. Journal of Endodontics. 2003; 29(3): p. 170-175.

[8]. Torabinejad $\mathrm{M}$, et al., The antimicrobial effect of MTAD: an in vitro investigation. Journal of Endodontics. 2003; 29(6): p. 400-403.

[9]. Ostby N. Chelating in root canal therapy. Ethylene-diamine tetraacetic acid for cleansing and widening of root canals. Odontol Tidskr. 1957; 65: p. 3-11.

[10]. Frithjof R. and BN Östby. Effect of edtac and sulfuric acid on root canal dentine. Oral Surgery, Oral Medicine, Oral Pathology. 1963; 16(2): p. 199-205.

[11]. Smith JJ and BE Wayman. An evaluation of the antimicrobial effectiveness of citric acid as a root canal irrigant. Journal of endodontics. 1986; 12(2): p. 54-58.

[12]. Nagayoshi M, et al., Bactericidal effects of diode laser irradiation on Enterococcus faecalis using periapical lesion defect model. ISRN dentistry, 2011.

[13]. Jaramillo D, et al., Efficacy of photon induced photoacoustic streaming (PIPS) on root canals 
infected with Enterococcus faecalis: a pilot study. Endod Prac. 2012; 5(3): p. 28-32.

[14]. Kho P and JC Baumgartner. A comparison of the antimicrobial efficacy of $\mathrm{NaOCl} /$ Biopure MTAD versus $\mathrm{NaOCl} / \mathrm{EDTA}$ against Enterococcus faecalis. Journal of endodontics. 2006; 32(7): p. 652-655.

[15]. Nara A, PC Dhanu, D Latha Anandakrishna. Comparative Evaluation of Antimicrobial Efficacy of MTAD, 3\% NaOCI and Propolis Against E Faecalis. International journal of clinical pediatric dentistry. 2010; 3(1): p. 21.

[16]. Siqueira Jr, JF, et al., Mechanical reduction of the bacterial population in the root canal by three instrumentation techniques. Journal of Endodontics. 1999; 25(5): p. 332-335.

[17]. Kuruvilla JR and MP Kamath. Antimicrobial activity of $2.5 \%$ sodium hypochlorite and $0.2 \%$ chlorhexidine gluconate separately and combined, as endodontic irrigants. Journal of Endodontics. 1998; 24(7): p. 472-476.

[18]. Türkün M, N Gökay, N Özdemir. Comparative investigation of the toxic and necrotic tissue dissolving effects of different endodontic irrigants. Istanbul Univ Dishekim Fak Derg. 1998; 32: p. 87-94.

[19]. Thomas AM., et al., Elimination of infection in pulpectomized deciduous teeth: a shortterm study using iodoform paste. Journal of endodontics. 1994; 20(5): p. 233-235.

[20]. Siqueira Jr J, et al., Evaluation of the effectiveness of sodium hypochlorite used with three irrigation methods in the elimination of Enterococcus faecalis from the root canal, in vitro. International endodontic journal. 1997; 30(4): p. 279-282.

[21]. Shabahang S, M Pouresmail and M Torabinejad. In vitro antimicrobial efficacy of MTAD and sodium hypochlorite. Journal of Endodontics. 2003;29(7): p. 450-452.

[22]. Molander A, C Reit and G Dahlen. The antimicrobial effect of calcium hydroxide in root canals pretreated with $5 \%$ iodine potassium iodide. Dental Traumatology. 1999; 15(5): p. 205-209.

[23]. Estrela C, et al., Antimicrobial evaluation of calcium hydroxide in infected dentinal tubules. Journal of endodontics. 1999; 25(6): p. 416-418.

[24]. Zhang W, M Torabinejad and Y Li. Evaluation of cytotoxicity of MTAD using the MTT-tetrazolium method. Journal of Endodontics. 2003; 29(10): p. 654-657.

[25]. Shabahang $S$ and $M$ Torabinejad. Effect of MTAD on Enterococcus faecalis-contaminated root canals of extracted human teeth. Journal of Endodontics. 2003; 29(9): p. 576-579.

[26]. Newberry BM, et al., The antimicrobial effect of biopure MTAD on eight strains of Enterococcus faecalis: an in vitro investigation. Journal of endodontics. 2007; 33(11): p. 1352-1354.

[27]. Portenier, I., et al., Killing of Enterococcus faecalis by MTAD and chlorhexidine digluconate with or without cetrimide in the presence or absence of dentine powder or BSA. Journal of Endodontics, 2006. 32(2): p. 138-141.

[28]. Ghoddusi J, et al., An evaluation of microbial leakage after using MTAD as a final irrigation. Journal of Endodontics. 2007; 33(2): p. 173-176.

[29]. Dunavant TR, et al., Comparative evaluation of endodontic irrigants against Enterococcus faecalis biofilms. Journal of endodontics. 2006; 32(6): p. 527-531.

[30]. Baumgartner, J.C., S. Johal, and J.G. Marshall. Comparison of the antimicrobial efficacy of $1.3 \%$ $\mathrm{NaOCl} / \mathrm{BioPure} \mathrm{MTAD}$ to $5.25 \% \mathrm{NaOCl} / 15 \%$ EDTA for root canal irrigation. Journal of Endodontics, 2007. 33(1): p. 48-51.

[31]. Krause TA, FR Liewehr and CL Hahn. The antimicrobial effect of MTAD, sodium hypochlorite, doxycycline, and citric acid on Enterococcus faecalis. Journal of Endodontics. 2007; 33(1): p. 28-30. 